\title{
Development of Adaptive Acoustic Impedance Control Technologies of Acoustic Duct Liner
}

\author{
Hiroshi Kobayashi, ${ }^{1}$ Schunichi Ozaki, ${ }^{2}$ and Makoto Yokochi ${ }^{2}$ \\ ${ }^{1}$ Japan Aerospace Exploration Agency, 1-12-14 Benten, Chiba, Urayasu 279-0026, Japan \\ ${ }^{2}$ Graduate School of Waseda University, 3-4-1 Oukubo, Shinjuku-Ku, Tokyo 169-8555, Japan \\ Correspondence should be addressed to Hiroshi Kobayashi, uh-koba@dg8.so-net.ne.jp
}

Received 13 December 2010; Revised 15 April 2011; Accepted 26 May 2011

Academic Editor: Marek Pawelczyk

Copyright ( 92011 Hiroshi Kobayashi et al. This is an open access article distributed under the Creative Commons Attribution License, which permits unrestricted use, distribution, and reproduction in any medium, provided the original work is properly cited.

\begin{abstract}
This paper describes the development of adaptive acoustic impedance control (AAC) technologies to achieve a larger fan noise reduction, by adaptively adjusting reactance and resistance of the acoustic liner impedance. For the actual proof of the AAC technology III performance, the advanced fan noise absorption control duct liner II was made on trial basis, with the simple control system and the plain device. And, then, the duct liner II was examined for the AAC technology I, II, and III models, using the high speed fan test facility. The test results made clear that the duct liner II of the AAC technology III model could achieve the fan noise reduction higher than O.A. SPL $10 \mathrm{~dB}(\mathrm{~A})$ at the maximum fan speed $6000 \mathrm{rpm}$, containing the reduction of fundamental $\mathrm{BPF}$ tone of $18 \mathrm{~dB}$ and $2 \mathrm{nd} \mathrm{BPF}$ tone of $10 \mathrm{~dB}$ in response to the fan peed change from 3000 to $6000 \mathrm{rpm}$.
\end{abstract}

\section{Introduction}

Recently, due to the strong demands by communities in the vicinity of airports, the new aircraft noise certification for the subsonic aircraft, ICAO Chapter 4, took effect in 2006 with the aim to reduce the aircraft noise.

The ICAO Chapter 4 becomes substantially stringent for the development of the new subsonic and supersonic transports. In order to overcome the stringent regulation and to solve the recent aircraft noise issues at night flight, is strongly required the large reduction of the intensive fan noise emitted from the multistage fan in the supersonic transport engines, over the wide engine operational range.

In order to provide the adequate fan noise reduction, the fan noise suppressors need to be satisfied with the following demands (I) (VI) at least. The demand (I) is that suppressors are comparatively the simple and cheap devices and the systems to reduce both the fan and turbine tones and the broadband noise and to make the larger decrease in the O.A. SPL of $\mathrm{dB}$ (A) estimation. The demand (II) is to make it possible to reliably reduce fan noise, even if the mistuning, the response lag, and the nonoperation in their control systems would occur. The (III) is to provide with the reinforcement of the lower frequency fan tone reduction and with the enlargement of the reducible frequency band and to make it possible to adaptively reduce noises in the fast response to the fan speed change. The (IV) is to make it possible to reduce noises under the conditions contaminated with the oil, the water, and the fuel, under the intensive noise pressure level condition (SPL level of $150 \mathrm{~dB}$ to $160 \mathrm{~dB}$ ), and under the higher temperature condition $(900 \mathrm{~K})$ for turbine use. The $(\mathrm{V})$ is to make it possible to reduce the lower frequency fan noise with the shallower acoustic resonant chamber than ones required for the reduction of the lowest frequency fan tone. The (VI) is to shift the adaptive spectrum peak frequency (frequency shift more than 200\%) and to make the increase of the adaptive peak spectrum.

As one of the fan noise suppressors satisfied with these demands, the application of the active noise control (ANC) technology by cancelling the fan tones with the secondary noise sources is considered, which is developed by the other researchers and the authors in [1-3]. Figure 1 shows the test result of fan 1st BPF tone reduction by the active noise control (ANC) technology using the 16ch ANC devices. The 1 st $\mathrm{BPF}$ tone is reduced by SPL $15 \mathrm{~dB}$ at the maximum, but it is only the $0.48 \mathrm{~dB}(\mathrm{~A})$ reduction in the $\mathrm{dB}(\mathrm{A})$ estimates of 

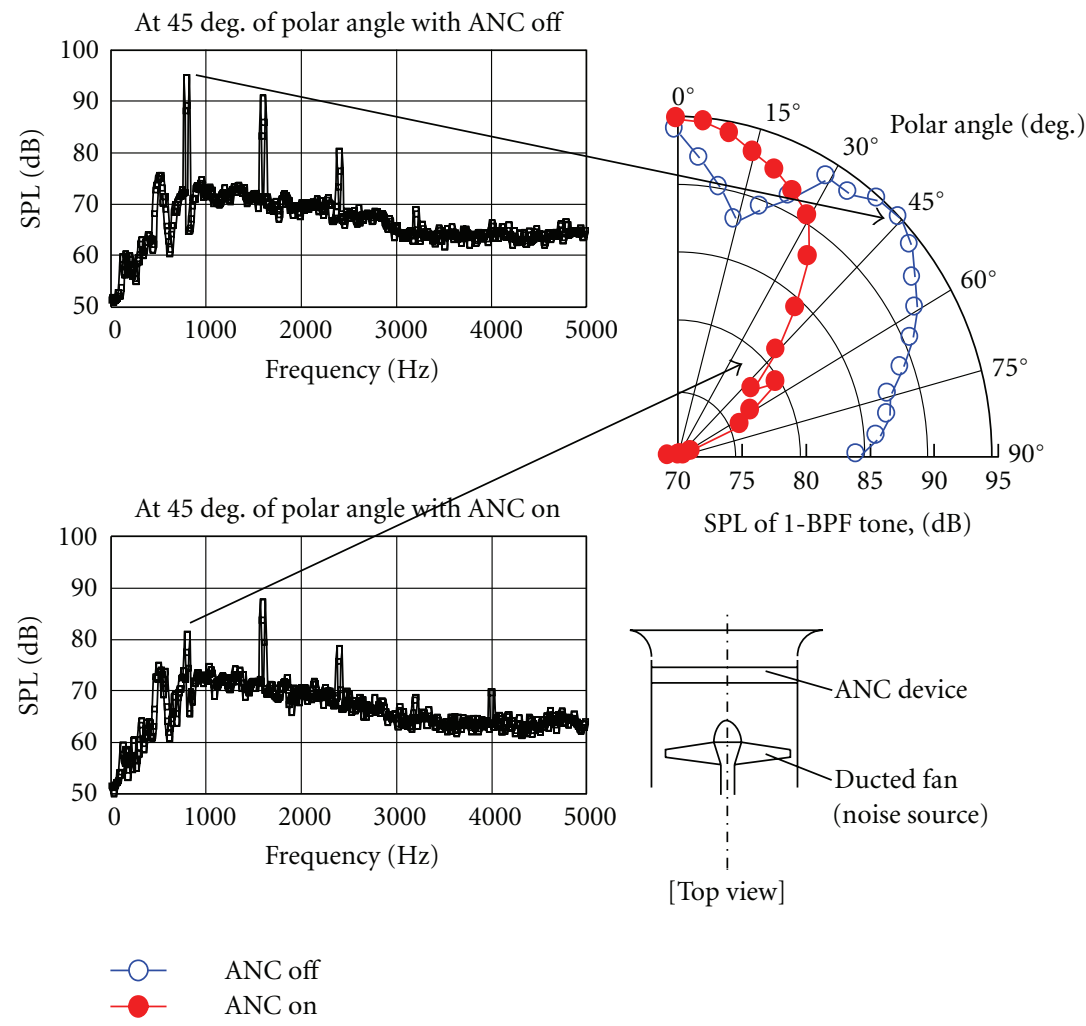

FIgURE 1: Fan 1st BPF tone reduction by ANC technology.

O.A. SPL. Table 1 describes the comparison of the property and the method between the AAC technology and the ANC technology, in order to easily understand the concept of the AAC technology. The AAC technology is the technology of the fan noise absorption, by adaptively controlling the acoustic impedance of the duct liners with apparatuses. The ANC system for canceling the multiple acoustic modes of fan tone must be composed of many generators of the spinning modes with the secondary noise source array, the amplifiers, the noise generators, the multichannel synthesizers, and the phase shifters. Therefore, the system becomes complicated and expensive. In addition, for the turbofan engine noise reduction, the ANC can hardly cancel the intensive fan tone due to the output power lack of the secondary noise source. Only the 1 to 2 PNL dB level can be reduced, even if whole fan tones could be canceled [3].

Furthermore, the acoustic liners with the tunable wall impedance control are researched [4]. The tunable acoustic liners make the small peak frequency shift and make the small increase of the absorptive spectrum. And the frequency range absorbed by the tunable acoustic liner is narrow. Furthermore, the acoustic liners with the tunable wall impedance control are researched [4]. The tunable acoustic liners make the small peak frequency shift and make the small increase of the absorptive spectrum. And the frequency range absorbed by the tunable acoustic liner is narrow. Neither these two fan noise reduction means nor fan noise suppressors developed previously by many researchers [5-7] seem to be able to respond to the six demands.
Therefore, at JAXA (Japan Aerospace Exploration Agency), adaptive acoustic impedance control (AAC) technology I was contrived and developed. The technology aims at absorbing both the fan tones and the broadband noise largely and reliably, by controlling the acoustic impedance of the acoustic duct liners with the mobile reflective plates. For largely decreasing the low frequency fan tones in the AAC technology I, the resonance of their tones with the acoustic resonant chamber, where the Honeycomb structure panel is removed, is made full use of, in addition to the onefourth wave length resonance with the resonant chamber depth. Because the Honeycomb structure panel is removed, the chamber space is enlarged in the transverse directions parallel to the duct liner surface plate. When the transverse dimensions of the resonant chamber are further larger than the chamber depth dimension, the fundamental resonant frequency of the resonant chamber becomes lower than the lowest frequency of the one-fourth wave length. Therefore, in the adaptive duct liners, the shallower resonant chamber depth than the ordinarily used chamber depth can be used. In addition, the acoustic absorbent materials stuck on the resonant chamber surface can reinforce the low frequency noise reduction $[8]$.

In the succession of the AAC technology I, the AAC technology III was contrived and developed using both the mobile reflective plate apparatus (AAC technology I model) and the tunable perforated plate apparatus (AAC technology II model) set in the acoustic duct liners, in order to adaptively adjust both the reactance and the resistance of the acoustic 
TABLE 1: Comparison of property and method between AAC technology and ANC technology.

\begin{tabular}{|c|c|c|}
\hline & AAC technology & ANC technology \\
\hline (1) Technology name & $\begin{array}{l}\text { Adaptive acoustic impedance control } \\
\text { technology }\end{array}$ & Active noise control technology \\
\hline (2) Noise reduction method & Adaptively controlled sound absorption & Actively controlled sound cancellation \\
\hline (3) Reduced noise contents & Both tones and broadband noise & Tones or broadband noise \\
\hline (4) Control target & $\begin{array}{l}\text { Maximum noise reduction in overall } \\
\text { sound pressure level }\end{array}$ & $\begin{array}{l}\text { Maximum tone reduction in sound } \\
\text { pressure level }\end{array}$ \\
\hline $\begin{array}{l}\text { (5) Extension to low frequency } \\
\text { noise region reduction }\end{array}$ & $\begin{array}{l}\text { Usage of acoustic resonance and } \\
\text { absorption in acoustic resonant chamber } \\
\text { space }\end{array}$ & $\begin{array}{l}\text { Usage of low frequency sound generated } \\
\text { by speakers }\end{array}$ \\
\hline $\begin{array}{l}\text { (6) Control method and } \\
\text { procedure }\end{array}$ & $\begin{array}{l}\text { (i) Large peak frequency shift and peak } \\
\text { level increase in acoustic absorption } \\
\text { spectra of duct liner for tones and } \\
\text { broadband reduction, by adjusting } \\
\text { reactance and resistance parts of acoustic } \\
\text { impedance of liner with mobile reflective } \\
\text { plate apparatus and tunable perforated } \\
\text { plate apparatus }\end{array}$ & $\begin{array}{l}\text { (i) Determination of acoustic spinning } \\
\text { modes of tones with microphone array } \\
\text { measuring systems and acoustic modal } \\
\text { analyzer. } \\
\text { (ii) Generation of spinning modes with } \\
\text { secondary noise source array, amplifiers, } \\
\text { noise generator, and multichannel } \\
\text { synthesizer. } \\
\text { (iii) Matching and cancelling spinning } \\
\text { modes of tones with phase shifter }\end{array}$ \\
\hline $\begin{array}{l}\text { (7) Feedback control system of } \\
\text { technology }\end{array}$ & Simple and plain feedback control system & $\begin{array}{l}\text { Complicated feedback control for } \\
\text { multi-channel system }\end{array}$ \\
\hline \multirow[t]{2}{*}{ (8) Available range of technology } & Low-high intensive sound (Max. $170 \mathrm{~dB}$ ) & $\begin{array}{l}\text { Low-medium intensive sound (Max. } \\
120 \mathrm{~dB})\end{array}$ \\
\hline & Low-high temperature (Max. $900 \mathrm{~K}$ ) & Low temperature (Max. $350 \mathrm{~K}$ ) \\
\hline
\end{tabular}

liner impedance. For the actual proof of the AAC technology III performance, the advanced fan noise absorption control duct liner II was made on trial basis, with the simple control system and the plain device. The duct liner II was examined for each of the AAC technology I, II, and III models, using the high speed fan test facility.

The test results made clear that the duct liner II is available as the excellent fan noise suppressor for the current and future aircraft engines. And it is applied for reducing the wide noise fields of the turbomachinery noise and the factory noise. The duct liner II could achieve the fan noise reduction higher than the O.A. SPL $10 \mathrm{~dB}(\mathrm{~A})$ at the max fan speed of $6000 \mathrm{rpm}$, containing the reduction of fundamental BPF tone of $18 \mathrm{~dB}$ and of $2 \mathrm{nd}$ BPF tone of $10 \mathrm{~dB}$ in the fan speed range from 3000 to $6000 \mathrm{rpm}$. It can provide with noise suppressors having the small weight, the small installation thrust loss, and the high noise reduction for aircraft engines. The AENC technology is composed of the adaptive acoustic impedance control (AAC) technology and the active jet noise control (AJC) technology.

Figure 2 shows the concept of the AENC technology and pictures of the fan inlet and the fan exhaust adaptive noise absorption control duct liner made for the actual proof of the AAC technology. The AAC technology absorbs both the tones and the broadband noise of fan, compressor, and turbine in the duct propagation process, by adaptively adjusting the acoustic impedance of the duct liners.

This paper describes each of the development of AAC technologies I, II, and III and the main results of the actual proof test of the AAC technology I, II, and III models with the acoustic duct liner II.

\section{Adaptive Acoustic Impedance Control Technologies I, II, and III}

Table 2 describes the comparison of property and method of the AAC technologies I, II, and III, in order to easily understand the concept of the adaptive acoustic impedance control technology. The adaptive acoustic impedance control technologies I, II, and III and the adaptive duct liner II have mainly property merits of low frequency noise reduction, reliable noise reduction, and high response noise reduction against fan noise change.

Figure 3 illustrates the concept of AAC technology I, using an example applied for adaptive duct liners. The duct liner is divided into four annular sectors and the each sector is produced with sound absorption panels and a mobile reflective plate. In each sector, a honeycomb structure panel is removed [9]. The duct liner is composed of a sound absorption part and an active control system part. The sound absorption part is made of a surface perforated plate, a wire mesh, and an acoustically lined mobile reflective plate. And the acoustic resonant chamber was constructed with four side plates and the duct casing wall stuck on the inside surface by porous absorbent materials. The acoustic resonant chamber space, where Honeycomb structure panel is moved, is enlarged in transverse directions parallel to the duct liner 


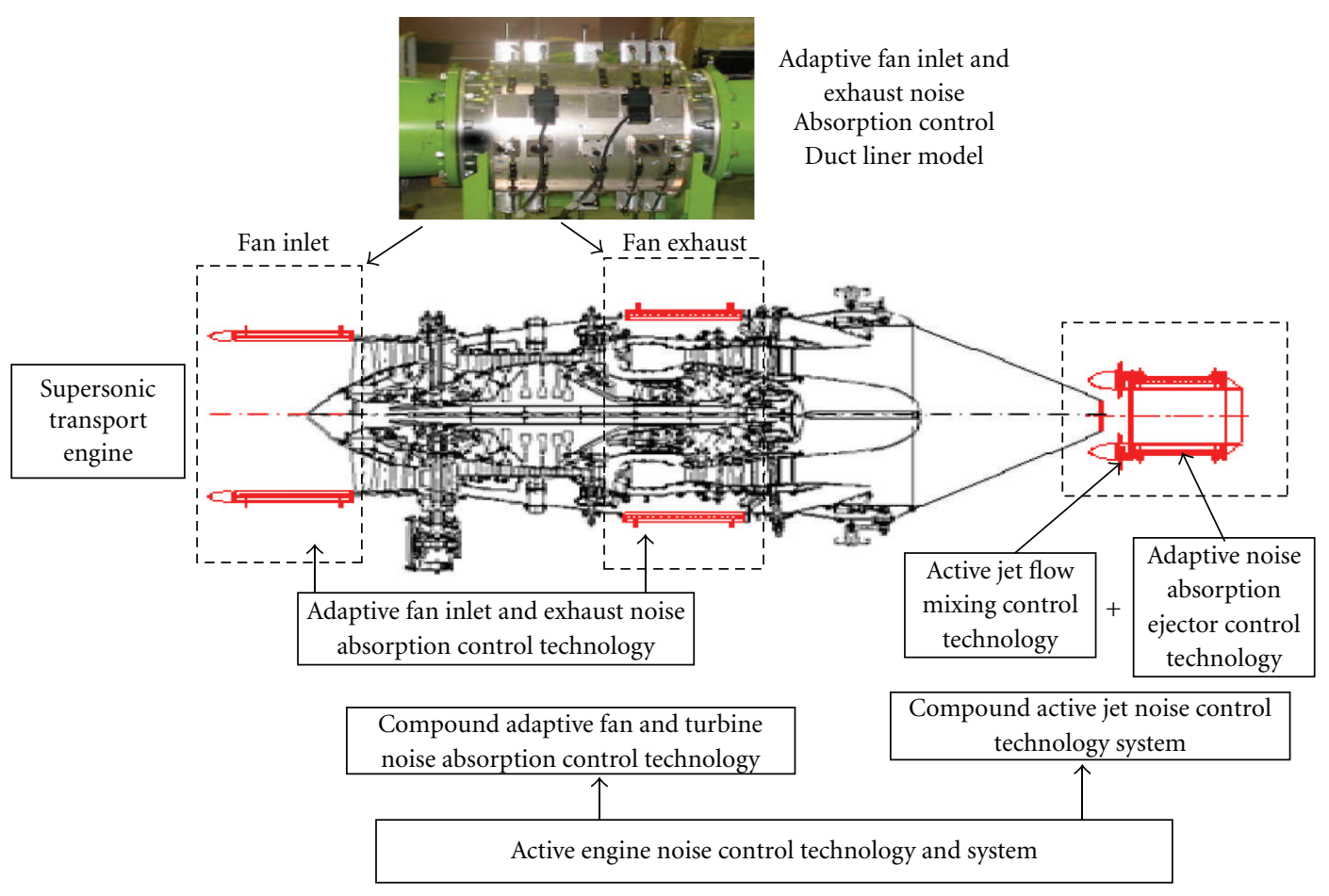

FIGURE 2: Concept of active engine noise control technology and pictures of adative noise absorption control duct liners.

TABLE 2: Three models of AAC technology I, II, and III.

\begin{tabular}{llll}
\hline & $\begin{array}{l}\text { AAC technology } \\
\text { I model }\end{array}$ & $\begin{array}{l}\text { AAC technology } \\
\text { II model }\end{array}$ & $\begin{array}{l}\text { AAC technology } \\
\text { III model }\end{array}$ \\
\hline $\begin{array}{l}\text { (1) Usage of } \\
\text { apparatus }\end{array}$ & $\begin{array}{l}\text { Mobile reflective } \\
\text { plate apparatus }\end{array}$ & $\begin{array}{l}\text { Tunable } \\
\text { perforated plate } \\
\text { apparatus }\end{array}$ & $\begin{array}{l}\text { Both mobile } \\
\text { reflective plate } \\
\text { and tunable } \\
\text { plate } \\
\text { apparatuses }\end{array}$ \\
\hline $\begin{array}{l}\text { (2) Mainly } \\
\text { controllable } \\
\begin{array}{l}\text { acoustic } \\
\text { impedance } \\
\text { part of liner }\end{array}\end{array}$ & $\begin{array}{l}\text { Reactance part } \\
\text { of acoustic } \\
\text { impedance of } \\
\text { liner }\end{array}$ & $\begin{array}{l}\text { Resistance part } \\
\text { of acoustic } \\
\text { impedance of } \\
\text { liner }\end{array}$ & $\begin{array}{l}\text { Both reactance } \\
\text { and resistance } \\
\text { parts of acoustic } \\
\text { impedance of }\end{array}$ \\
\hline
\end{tabular}

surface sheet, and it aims at increasing the frequency region of fan noise absorption, especially low frequency region.

The active control system comprises sensing sensors, a multistepping motor control device, stepping motor equipments installed on the panel casing wall, and a mechanics jointed to the motor equipment. The mechanics is consisted of pin joints, rods, arms, and gears for moving the reflective plates in three modes of parallel shift, forward shift and backward shift. The motor control device consisted of a personal computer, a bus bridge unit, stepping motor control boards, and stepping motor drivers connecting to the stepping motor equipments.

We try to explain the control system and control algorithm when in advance the order of moving modes of the mobile reflective plate is decided and the fan rotates at constant speed. The new position of mobile reflective plate is searched in the region covered by limiters, obeying the LMS (least mean square) algorithm, and the signal of displacement sensor sensing the movement of mobile reflective plate is sent to computer. The position of mobile reflective plate is changed so that the minimum value of overall SPL can be caught by the sensing sensor of a microphone set in the anechoic chamber room or a miniature pressure transducer set on the duct casing. Then, the moving mode and position of the mobile reflective plate and the minimum overall SPL are stored in the computer. The computer sends the pulse to stepping motor drive control, and the mobile reflective plate is moved to the position of the minimum O.A. SPL by the stepping motor equipments.

When the movement of mobile reflective plate is stopped by the limiters and the next moving mode is set, the same feedback loop is circulated. From the stored overall SPL, the minimum overall SPL is determined as well as the mode and the position of mobile reflective plate. Finally, the mode and the position of the mobile reflective plate return to ones where the overall SPL becomes the minimum value. When other fan rotational speed is fixed, the same operational technique is conducted in order to determine the mode and the position of the mobile reflective plate and the minimum overall SPL at the fan speed.

The AAC technology I makes an large peak frequency shift and a big peak spectra increase of the acoustic absorption spectra of duct liner for large fan noise reduction, by adjusting the reactance of acoustic impedance of the duct liner with the control of reflective plate movement in response to fan speed change. Through these experiments, the acoustic impedance of the duct liner is neither measured 


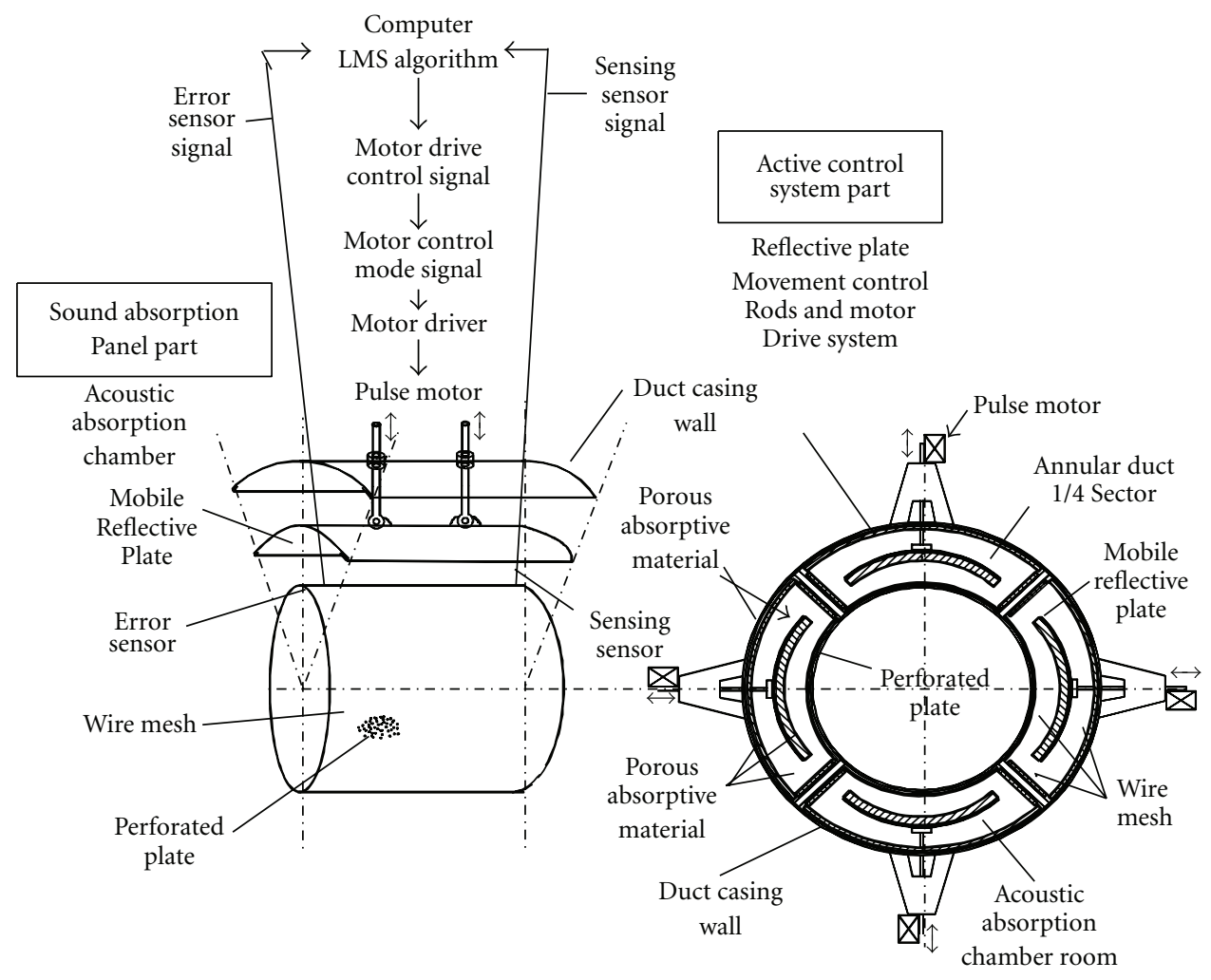

FIGURE 3: Concept of adaptive acoustic impedance control technology I (mobile reflective plate apparatus—reactance part control of acoustic impedance).

nor analyzed. However, in AAC Technology I, the acoustic absorption act is considered to largely depend on the acoustic resonance of duct liner and, therefore, the control of the reflective plate movement in the acoustic resonant chamber is considered to largely affect the reactance of the acoustic impedance of the duct liner.

The acoustic absorption mechanism of AAC technology I is considered to be composed of the resonance of incident sound with the acoustic resonant chamber, of noise absorption by acoustic absorbent materials stuck on the acoustic chamber wall, and of noise absorption by acoustic absorbent materials stuck on the mobile reflective plate. For largely decreasing low frequency fan tones by the AAC technology $\mathrm{I}$, the resonance of their tones with the acoustic resonant chamber is made full use of, in addition to one-fourth wave length resonance with the resonant chamber depth. When transverse dimensions of the resonant chamber are further larger than the chamber depth dimension, the fundamental frequency of resonant modes of the resonant chamber becomes lower than the lowest frequency of one-fourth wave length resonance. Therefore, for the adaptive duct liners, the shallower resonant chamber depth than the ordinarily used chamber depth can be applied. As an example, to obtain the one-fourth wave length resonance with the chamber depth (frequency $270 \mathrm{~Hz}$ ), the chamber depth is necessary to be $315 \mathrm{~mm}$, while, the chamber depth of adaptive duct liner is sufficient to be about $100 \mathrm{~mm}[8,10]$, while the acoustic absorption control mechanism is considered to depend on the variations of the mobile reflective plate movement and of the acoustic resonant chamber space; namely, there are the variation of distance between the perforated surface plate and the mobile reflective plate (Helmholtz resonance effect), the variation of nonuniformly distance between the inclined mobile reflective plate and the perforated surface plate, the variation of the acoustic chamber space divided by the mobile reflective plate movement, and the variation of sound incident angles to the inclined mobile reflective plate.

When fan noise changes in accordance with fan speed change, the acoustic impedance of the duct liner is adaptively controlled using the AAC technology I. The AAC technology I makes a large peak frequency shift and a big peak spectra increase of the acoustic absorption spectra of the duct liner for large fan noise reduction, by adjusting the reactance of acoustic impedance of the duct liner with the control of the reflective plate movement, in response to fan speed change. Figure 4 shows a cut view and pictures of the acoustic absorption chamber, the mobile reflective plate, and the mechanics controlling the mobile reflective plate.

Figures 5 and 6 show the duct liner application of the AAC technology II using the tunable perforated plate apparatus, and the pictures of mechanics and components of the tunable perforated plate apparatus, respectively. The duct liner is divided into four annular sectors, and each sector is composed of the sound absorption and the control system. The sound absorption has the same acoustic resonant chamber as the AAC technology I, and, in the chamber, 


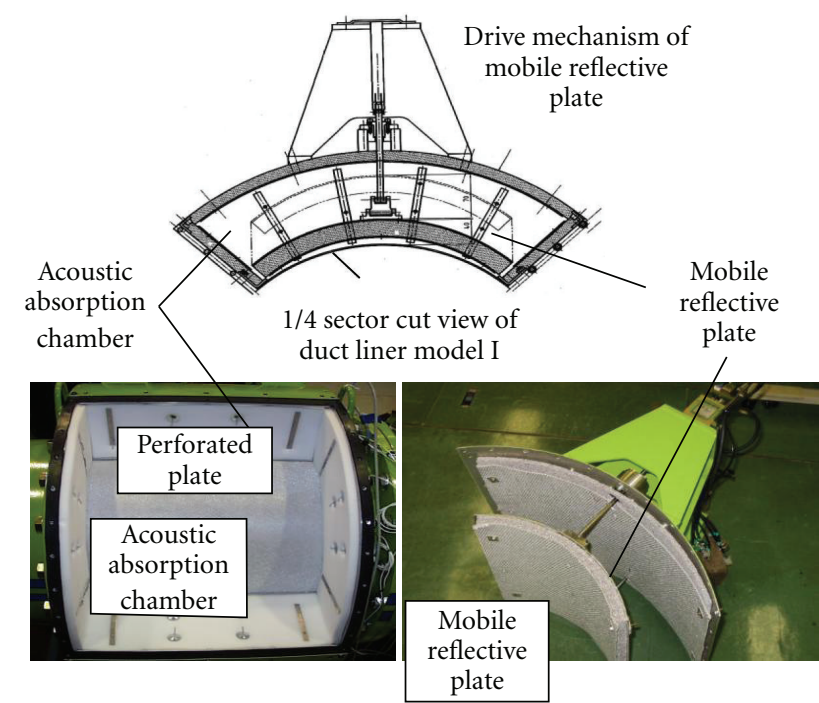

FIgURE 4: Cut view and pictures of acoustic absorption chamber, mobile reflective plate, and mechanics controlling mobile reflective plat impedance.

the tunable perforated plate apparatus is arranged. The apparatus is composed of the fixed perforated plate and the perforated plate slid by a rack-pinion assembly, so that the porosity of the apparatus can be varied. The control system controls the apparatus by the mechanism similar to the AAC technology I. The signal of displacement sensing sensor sent to the motor control device controls the stepping motor equipments. And the signal determines the porosity of the tunable perforated plate apparatus, so that the overall SPL measured by the sensing sensor of the miniature pressure transducer can reach to the minimum of overall SPL.

Through the experiments, the acoustic impedance of the duct liners is neither measured nor analyzed. However, in the AAC technology II, sound absorption is considered to depend on the porosity variation of the perforated plate apparatus and, therefore, the tunable perforated plate is considered to largely affect the acoustic resistance of the duct liners.

Figure 7 shows the duct liner concept and a schematic view of the structure of the AAC technology III, and the chamber room of the duct liner is combined with both the tunable perforated plate apparatus and the mobile reflective plate apparatus. The adaptive control system of the duct liner controls the both apparatuses by the mechanism similar to the AAC technology I and II. The signals of the displacement sensing sensor are sent to the motor control devices. And it controls the stepping motor equipments and determine both the position and the mode of the mobile reflective plate apparatus, and the porosity of the tunable perforated plate apparatus, so that the overall SPL measured by the sensing sensor of miniature pressure transducer can reach to the minimum of overall SPL.

\section{Test Facility and Test Procedure}

The adaptive fan noise absorption control duct liner II was made on trial base, and the AAC technology I, II, and
III models of the duct liner II were examined using a high speed fan test facility. In Figure 8 are shown pictures of the adaptive duct liner II adjusting both the reactance and resistance of the acoustic impedance of the duct liner with both the mobile reflective plate apparatus and the tunable perforated plate apparatus. The duct liner II has outer diameter $524 \mathrm{~mm}$, inner diameter $364 \mathrm{~mm}$, and duct length $400 \mathrm{~mm}$. The fixed perforated plate of the duct liner surface has plate thickness $1 \mathrm{~mm}$, hole diameter $1.0 \mathrm{~mm}$, hole pitch $2.0 \mathrm{~mm}$, and porosity $22.6 \%$. Aluminum wire woven mesh plate (Poal) is stuck on the sliding perforated plate. Aluminum wire woven mesh plate and aluminum porous absorbent mat or polyurethane foam mat (Acousticel) are stuck on the inner surface of the mobile reflective plate and on the inner wall of the acoustic resonant chamber.

Figure 9 shows a general view and a picture of the high speed fan test facility where the adaptive duct liner is set to examine its acoustic performance. The model fan is used as a noise source. The fan is consisted of 16 swept rotor blades and 15 rods so that steady and large fan tones can be generated even at low fan speeds. The test facility comprises the adaptive duct liner II, an adaptive control system, a model fan driven by a $400 \mathrm{~kW}$ motor, an anechoic room, and an acoustic measuring system. The one end of fan inlet duct opens in the anechoic room, and the other duct end is connected to the model fan.

The far-field fan noise is measured at $10 \mathrm{deg}$. intervals between 0 and $90 \mathrm{deg}$. from the fan axis in the anechoic room, by a microphone array set on the circle of $1.5 \mathrm{~m}$ radius from the fan inlet center. Also, the in-duct fan noise is measured with flush-mounted microphones installed upstream and downstream of the adaptive duct liner II. The microphone signals are amplified by the acoustic measuring Amps and analyzed with a FFT digital analyzer.

The noise reduction and the response performance of the adaptive duct liner II for the AAC technology I, II, and III models were examined using the high speed fan test facility. The AAC technology model of the adaptive duct liner II was exchanged, and the experiments were conducted for the AAC technology I model (mobile reflective plate apparatus), the AAC technology II model (tunable perforated plate apparatus), and the AAC technology III model (both the mobile reflective plate apparatus and the tunable perforated plate apparatus). And the position and the moving mode of the mobile reflective plates and the porosity of the tunable perforated plates were selected, at an interval of $1000 \mathrm{rpm}$ from 3000 to $6000 \mathrm{rpm}$. At each fan speed, when the overall SPL of far-field fan noise measured at the position of $60 \mathrm{deg}$. reaches to the lowest value, the chosen moving shift mode and the position of the mobile reflective plates, the porosity of the tunable perforated plates, and the measured fan noise data were recorded in the personal computer.

\section{Test Results and Discussion}

4.1. Absorption Performance of AAC Technology I Model (Mobile Reflective Plate Apparatus). The overall fan noise, 1st fan blade passing frequency (BPF) tone, 2nd BPF tone, and 


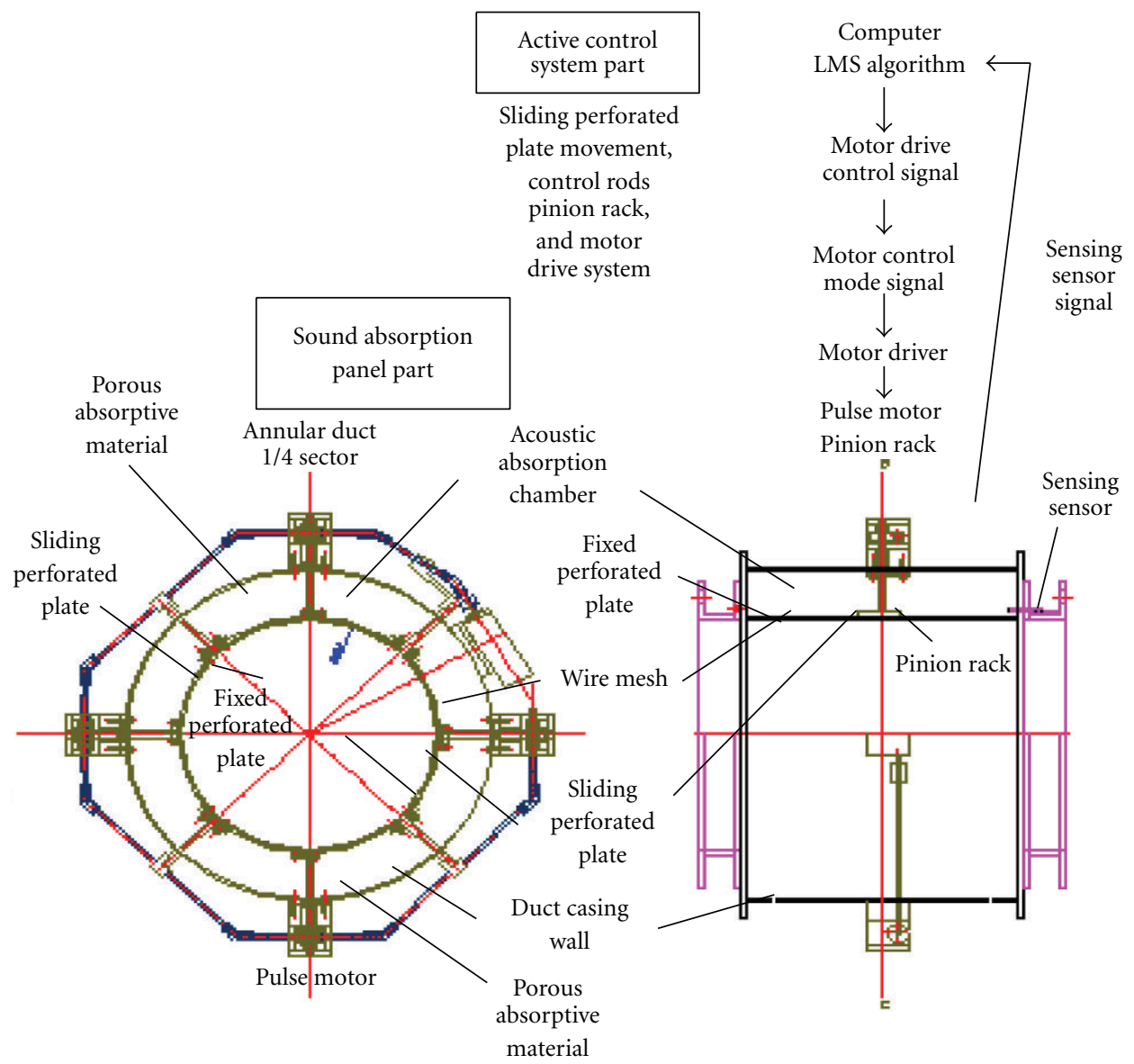

FIGURE 5: Concept of adaptive acoustic impedance control technology II (tunable perforated plate apparatus-resistance part control of acoustic impedance).

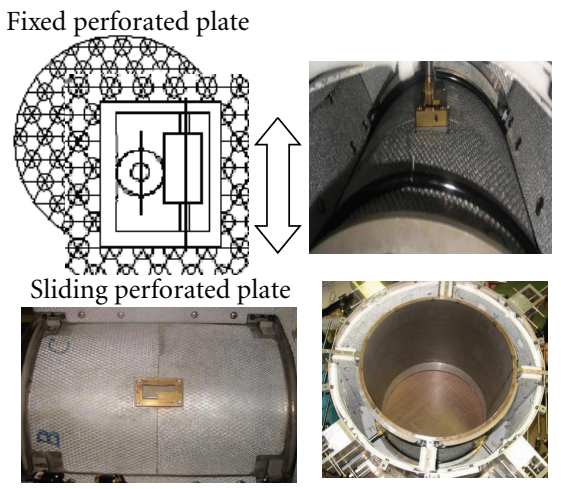

Figure 6: Tunable perforated plate apparatus of adaptive fan noise absorption control duct liner II.

3rd BPF tone reduced by the adaptive duct liner II of the AAC technology I model are shown in Figure 10, against the mobile reflective plate position. The mobile reflective plate position of the abscissa in the figure indicates the distance between a fixed surface perforated plate and the center of the mobile reflective plate. The figure describes that through the whole mobile reflective plate positions, fan noise of overall
SPL $13 \mathrm{~dB}(\mathrm{~A}), 1$ st BPF of $13 \sim 16 \mathrm{~dB}, 2$ nd BPF of $15 \sim 18 \mathrm{~dB}$, and $3 \mathrm{rd}$ BPF of $5 \sim 8 \mathrm{~dB}$ can be reduced by the duct liner II. In addition, it is clarified that the movement of the mobile reflective plates can control fan noise reduction, namely, fan overall SPL of $1 \mathrm{~dB}, 1$ st BPF of $3 \mathrm{~dB}, 2 \mathrm{nd} \mathrm{BPF}$ of $6 \mathrm{~dB}$, and 3rd BPF of $4 \mathrm{~dB}$.

Figure 11 shows that fan noise spectra reduced by the duct liner II of the AAC technology I model vary with the change of the mobile reflective plate position. The noise spectra reduction indicate the difference between spectra when the hard wall duct is used and the ones when the duct liner II is used. When the distance of the mobile reflective plates from the surface perforated plate increases, the noise spectra reduction increases in the middle frequency region of $0.5 \sim 2.0 \mathrm{kHz}$; however, it decreases in the high frequency region of $3.0 \sim 8.0 \mathrm{kHz}$. Observing in more detail, the noise spectra reduction is small in the frequency region higher than $8.0 \mathrm{kHz}$ and it becomes smaller in the frequency region of $4.0 \sim 6.0 \mathrm{kHz}$. In the frequency region of $3.0 \sim 4.0 \mathrm{kHz}$, the reduction is large at the small value of the mobile reflective plate position, while, in $2.0 \sim 3.0 \mathrm{kHz}$, the large reduction region becomes wide. In the low frequency region near $1.0 \mathrm{kHz}$, the reduction becomes large to be $19 \mathrm{~dB}$. Therefore, 


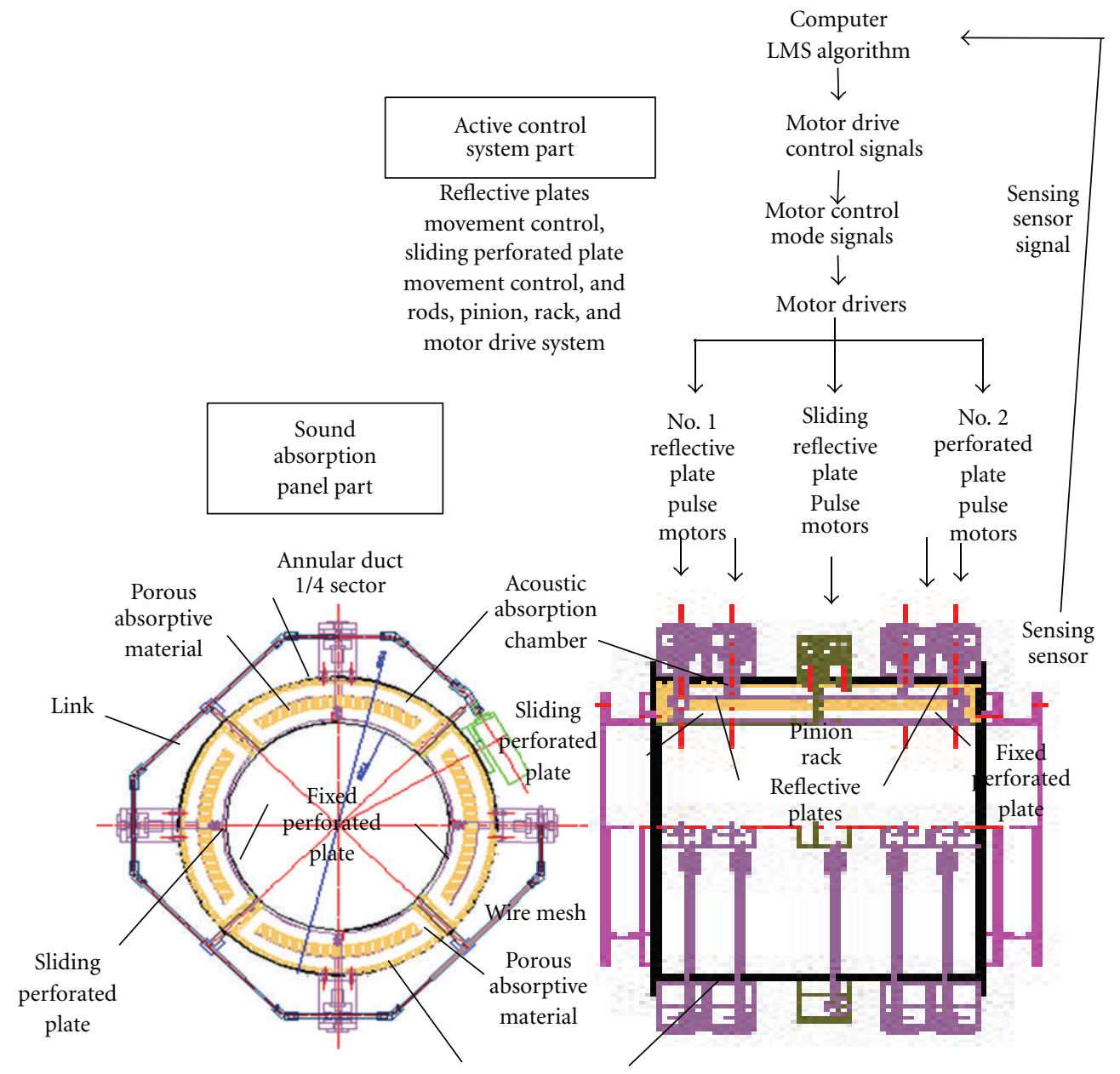

Figure 7: Concept of adaptive acoustic impedance control technology III (both mobile reflective plate apparatus and tunable perforated plate-two parts control of acoustic impedance of liner).
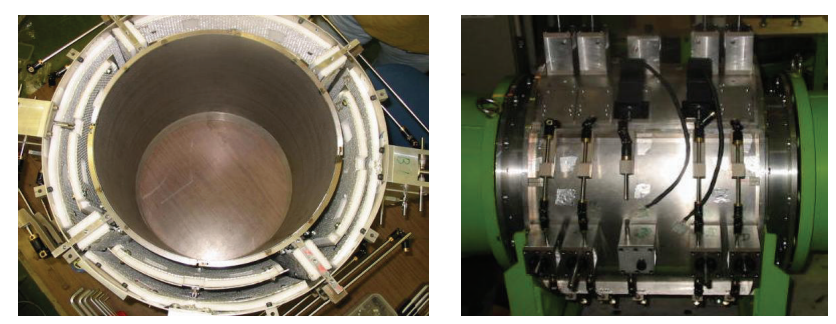

Figure 8: Adaptive fan noise absorption control duct liner II.

it is made clear that the noise reduction can be controlled by the movement of the mobile reflective plate.

The comparison of the effect of the mobile reflective plate shift modes between the case in the backward shift of mobile reflective plate and the case in the parallel shift of mobile reflective plate is shown in Figure 12, for the fan noise reduction of the adaptive duct liner II of the AAC technology I model, at the fan rotational speed of $4000 \mathrm{rpm}$. The case of the backward shift of mobile reflective plate describes the case when the mobile reflective plate is inclined so as to face to fan rotational surface. In the low frequency region near
$500 \mathrm{~Hz}$, the noise reduction of the backward shift is $19 \mathrm{~dB}$ and it is by $2.0 \mathrm{~dB}$ larger than the ones of the parallel shift. This experimental result makes clear that the noise spectra reduction can be varied by exchange of the shift mode of the mobile reflective plate.

Figure 13 shows the noise reduction in two cases of duct liner II with and without the mobile reflective plate. The difference between two noise spectra lines indicates the existence effect of the mobile reflective plate. When the mobile reflective plate is not used in the duct liner II, the noise reduction decreases over the wide frequency region. While, when the mobile reflective plate is used in the duct liner II, the noise reduction increases in the frequency region of $400 \sim$ $1000 \mathrm{~Hz}$ and, especially, at frequency of $800 \mathrm{~Hz}$ the eduction level becomes larger than $16 \mathrm{~dB}$, by an increment in $4.6 \mathrm{~dB}$.

\subsection{Absorption Performance of AAC Technology II Model} (Tunable Perforated Plate Apparatus). The variation of fan noise overall SPL reduction is shown in Figure 14, when the porosity of the tunable perforated plate apparatus in the duct liner II of the AAC technology II model changes at the fan rotational speed of $4000 \mathrm{rpm}$. When the porosity changes 


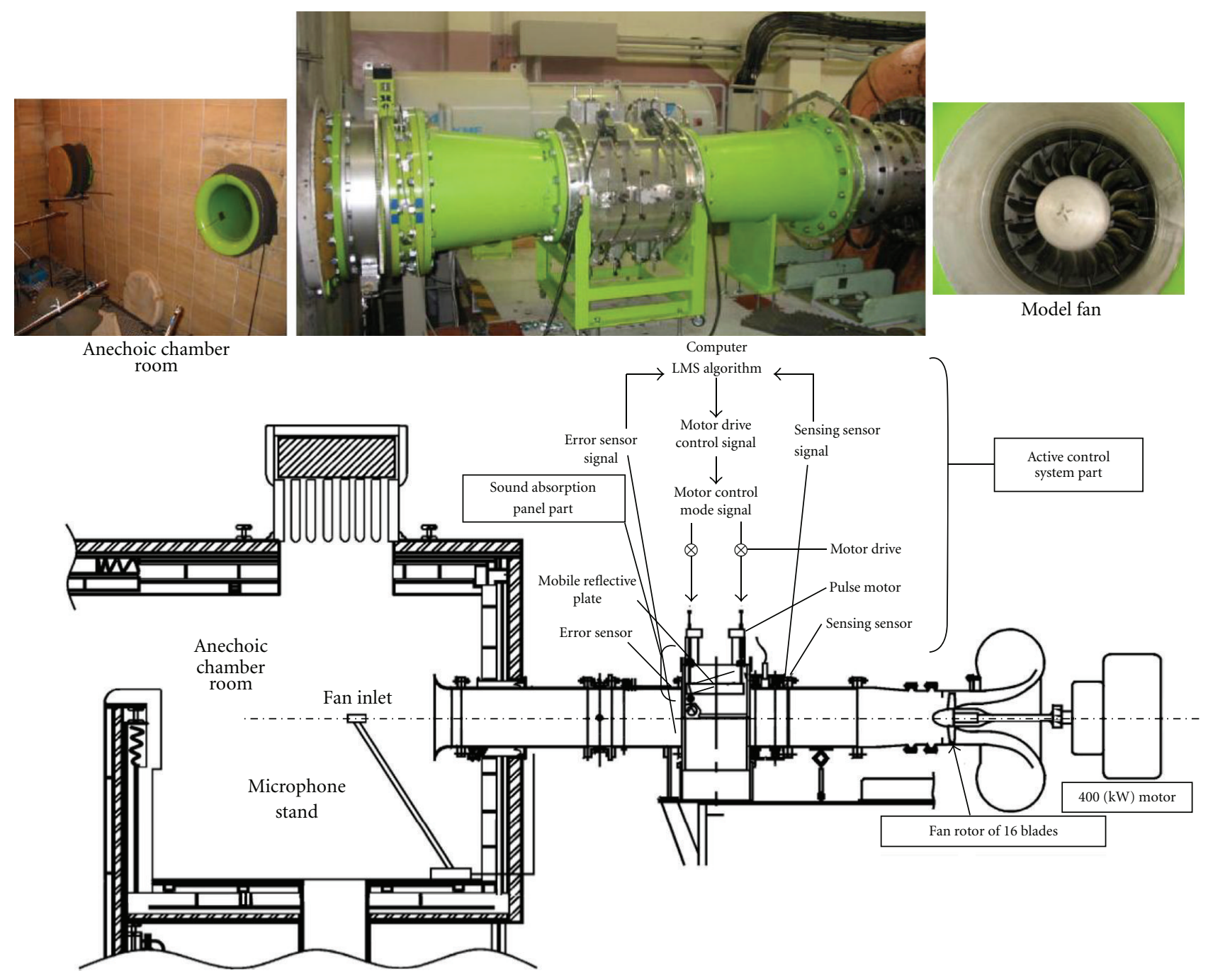

FIgURE 9: General view and picture of high speed fan test facility.

from $0.0 \%$ to $22.3 \%$, the variation of fan noise reduction is found to be about $0.8 \mathrm{~dB}$. While the experimental results obtained by Gaeta Jr. and Ahuja [4] clarify that the frequency region of the peak noise reduction is invariant and the change of fan noise reduction is $5.0 \mathrm{~dB}$, when the porosity of the tunable perforated plates changes from $0.2 \%$ to $19.6 \%$. Gaeta conducted these experiments using the flat shape tunable perforated plates; however, our experiment was conducted using the cylindrical shape tunable perforated plates. Therefore, it can be considered that, due to the experimental difficulty of construction, assembly, and tuning of the cylindrical shape tunable perforated plate apparatus, the fan noise reduction achieved by the cylindrical shape tunable perforated plate apparatus became smaller, in comparison with ones obtained by flat shape tunable perforated plate apparatus.

The fan noise overall SPL reduction is shown in Figure 15 when the fixed perforated plate is combined with two kinds of the perforated plates slid in the tunable perforated plate apparatus. The fixed perforated plate has the plate thickness of $1.0 \mathrm{~mm}$, the hole diameter of $1.0 \mathrm{~mm}$, the hole pitch of $2.0 \mathrm{~mm}$, and the porosity of $22.6 \%$. While, in the two kinds of slid perforated plates, no. 1 has the plate thickness of $1.0 \mathrm{~mm}$, the hole diameter of $1.4 \mathrm{~mm}$, the hole pitch of $2.0 \mathrm{~mm}$, and the porosity of $45.0 \%$ and no. 2 has the plate thickness of $1.0 \mathrm{~mm}$, the hole diameter of $1.0 \mathrm{~mm}$, the hole pitch of $2.0 \mathrm{~mm}$, and the porosity of $22.6 \%$. The maximum porosity of two kinds of tunable perforated plate apparatus is the same, because fixed surface perforated plate is common. The fan noise overall SPL of two kinds of combination apparatus are larger than $10.0 \mathrm{~dB}(\mathrm{~A})$, but the difference of the overall SPL reduction is only $1.5 \mathrm{~dB}(\mathrm{~A})$. It is supposed that effects of the porosity difference between two kinds of slid perforated plates are not observed, because of the difficulty of construction and assembly of the cylindrical shape tunable perforated plate apparatus.

\subsection{Absorption Performance of AAC Technology III Model} (Tunable Perforated Plate Apparatus and Mobile Reflective Plate Apparatus). Figure 16 illustrates the fan noise spectra 


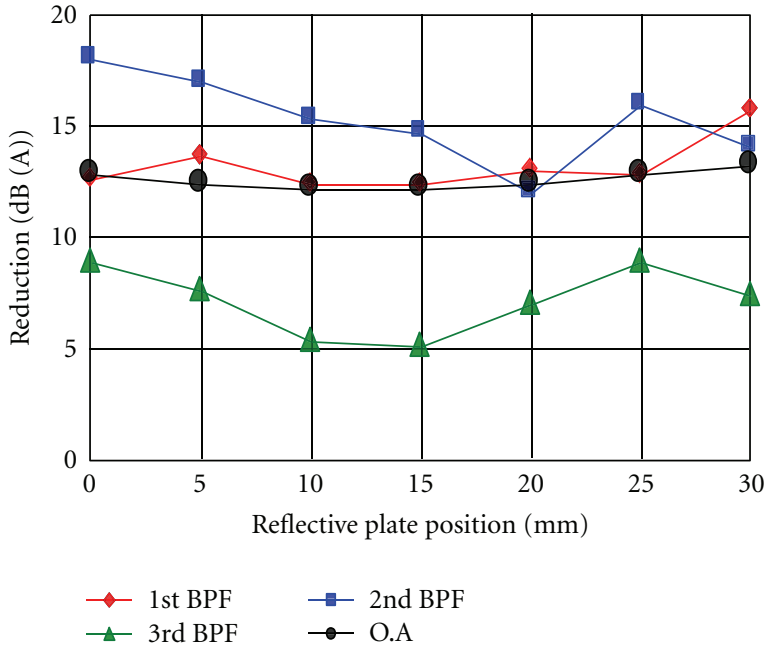

Figure 10: Variation of overall fan noise, 1st BPF, 2nd BPF, and 3rd $\mathrm{BPF}$ tones reduction by adaptive duct liner II of AAC technology I. Fan rotational speed $4000 \mathrm{rpm}$; acoustic measuring point $60 \mathrm{deg}$;; mobile reflective plate; parallel shift, acoustic absorbent material; poal + acousticel.

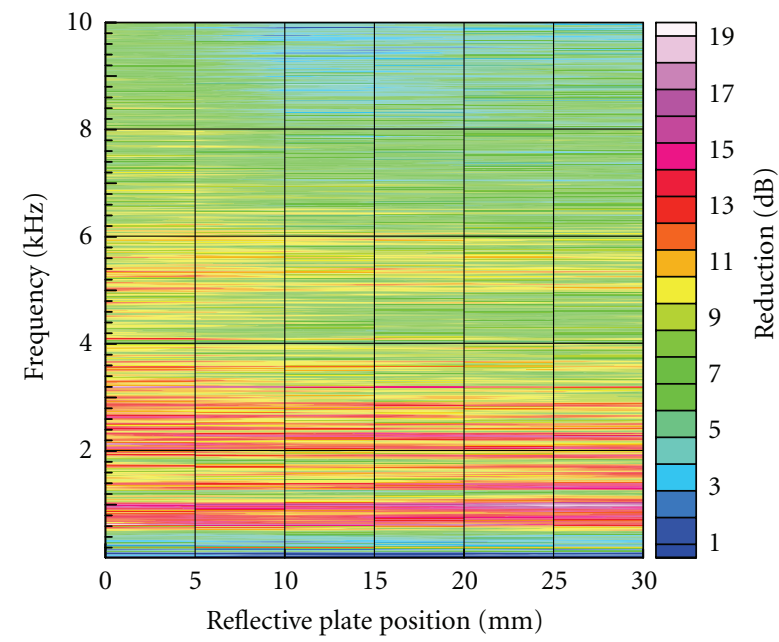

FIGURE 11: Variation of fan noise spectra reduction by adaptive duct liner II of AAC technology I model with mobile reflective plate position change. Fan rotational speed 4000 rom; acoustic measuring point 60 deg.; mobile reflective plate; parallel shift, acoustic absorbent material; poal + acousticel.

emitted from the fan inlet duct, in the both case when the duct liner II of the AAC technology III model is equipped in the fan inlet duct and in the case when the hard wall duct is equipped in it. The fan noise spectra are ones measured at the fan rotational speed of $6000 \mathrm{rpm}$ and at the microphone position of $60 \mathrm{deg}$. The difference of two fan noise spectra describes the fan noise spectra reduced by the duct liner II of the AAC technology III model. The fan noise reduction is $19 \mathrm{~dB}$ in the frequency region of the fan exhaust duct resonance $(900 \mathrm{~Hz}), 9 \mathrm{~dB}$ in $1 \mathrm{st} \mathrm{BPF}$ tone noise $(1.6 \mathrm{kHz})$, $11 \mathrm{~dB}$ in $2 \mathrm{nd} \mathrm{BPF}$ tone noise, $8 \mathrm{~dB}$ in $3 \mathrm{rd} \mathrm{BPF}$ tone noise, and $10 \mathrm{~dB}$ in broadband fan noise. And the fan overall SPL noise

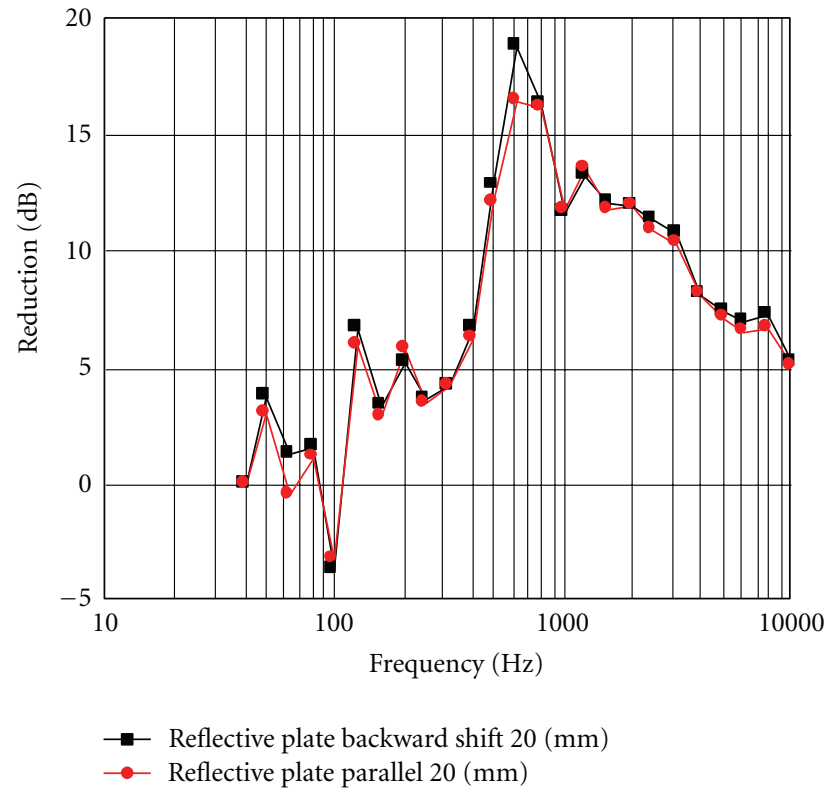

FIGURE 12: Effect of mobile reflective plate shift mode on fan noise spectra reduction by adaptive duct liner II of AAC technology I model. Fan speed $4000 \mathrm{rpm}$; measuring point 60 deg.; mobile reflective plate parallel shift and backward shift, acoustic absorbent material stuck on reflective plate; poal + acousticel.

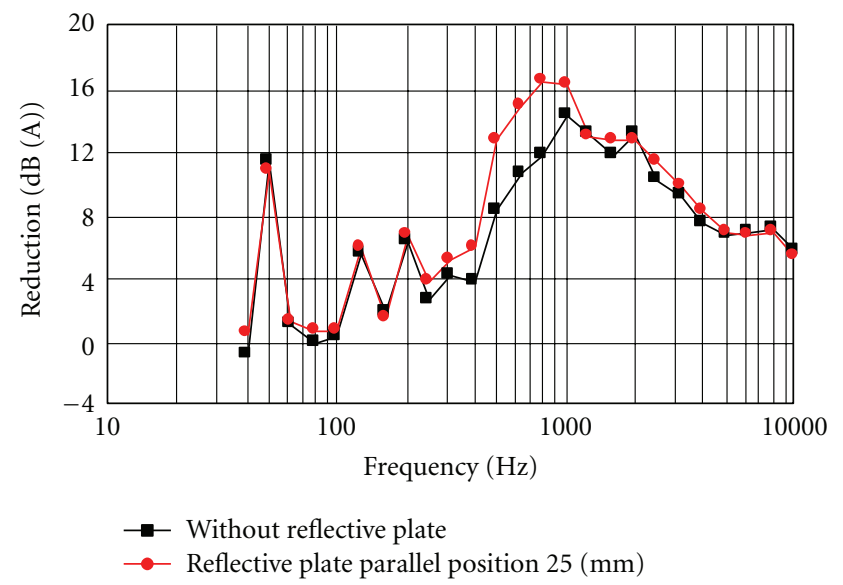

FIGURE 13: Fan noise spectra reduced by adaptive duct liner II of AAC technology I with and without mobile reflective plates. Fan speed $6000 \mathrm{rpm}$; measuring point $60 \mathrm{deg}$; with and without mobile reflective plates; acoustic absorbent material; poal + acousticel.

reduction by the duct liner II is $14.8 \mathrm{~dB}(\mathrm{~A})$. This value is 1.5 to 2.0 times of the fan overall SPL noise reduction achieved by the conventionally used duct liners. At the fan rotational speed from 3000 to $6000 \mathrm{rpm}$ is achieved the fan overall SPL noise reduction of larger than $10 \mathrm{~dB}(\mathrm{~A})$ by controlling both the mobile reflective plate and the tunable perforated plate apparatuses.

When the mobile reflective plate is fixed at $25 \mathrm{~mm}$ position and the porosity of the tunable perforated plate is changed, the variation of the fan overall SPL noise reduction 


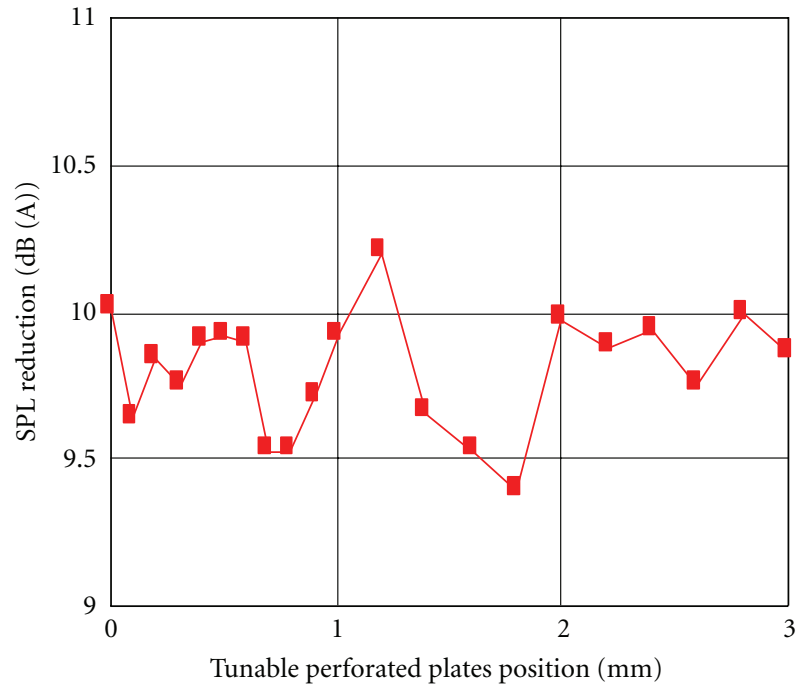

FIGURE 14: Variation of overall fan noise reduction by adaptive duct liner II of AAC technology II model with duct liner porosity change. Fan rotational speed $4000 \mathrm{rpm}$; acoustic measuring point 60 deg.; fixed perforated plate hole dia. $=1.0$; pitch $=2.0$ acoustic absorbent material stuck on plate; poal + acousticel.

is shown in Figure 17. The linear line of $12.5 \mathrm{~dB}$ is drawn in the figure, and it denotes the fan noise reduction value when both the positions of the mobile reflective plates and the tunable perforated plates are fixed. It is observed from Figure 17 that, by changing the tunable perforated plate position, namely, changing the porosity of the tunable perforated plate apparatus, the fan noise reduction scatters about $1.0 \mathrm{~dB}$ around the linear line, as same as the case of Figure 14.

In the case when the porosity of the tunable perforated plates is fixed and the mobile reflective plates are moved in the duct liner II and in the case when the porosity of the tunable perforated plates is fixed and the mobile reflective plates are removed from the duct liner II shown as the linear line of $10 \mathrm{~dB}$, the comparison of the fan overall SPL noise reduction is illustrated in Figure 18. The insertion of the mobile reflective plates leads to increase the fan overall SPL noise reduction of $2.0 \mathrm{~dB}$ (A). Its value scatters about $0.6 \mathrm{~dB}(\mathrm{~A})$ around the linear line of $12.0 \mathrm{~dB}$ and at the mobile reflective plate position of $5 \mathrm{~mm}$, the large fan noise reduction of $12.2 \mathrm{~dB}(\mathrm{~A})$ is achieved.

Figures 17 and 18 clarify that the insertion of the mobile reflective plate into the adaptive duct liner II largely contributes to fan noise reduction, as well as the acoustic resonant chamber.

The effect of the acoustic absorbent materials stuck on duct liner II against the fan noise spectra is shown in Figure 19. In the figure, two fan noise spectra are compared in cases when the aluminum wire woven mesh plate (Poal) plus the polyurethane foam mat (Acousticel) are used and in the case when only the polyurethane foam mat is used as the acoustic absorbent materials in the duct liner II. In the polyurethane foam mat, the fan noise absorption in-

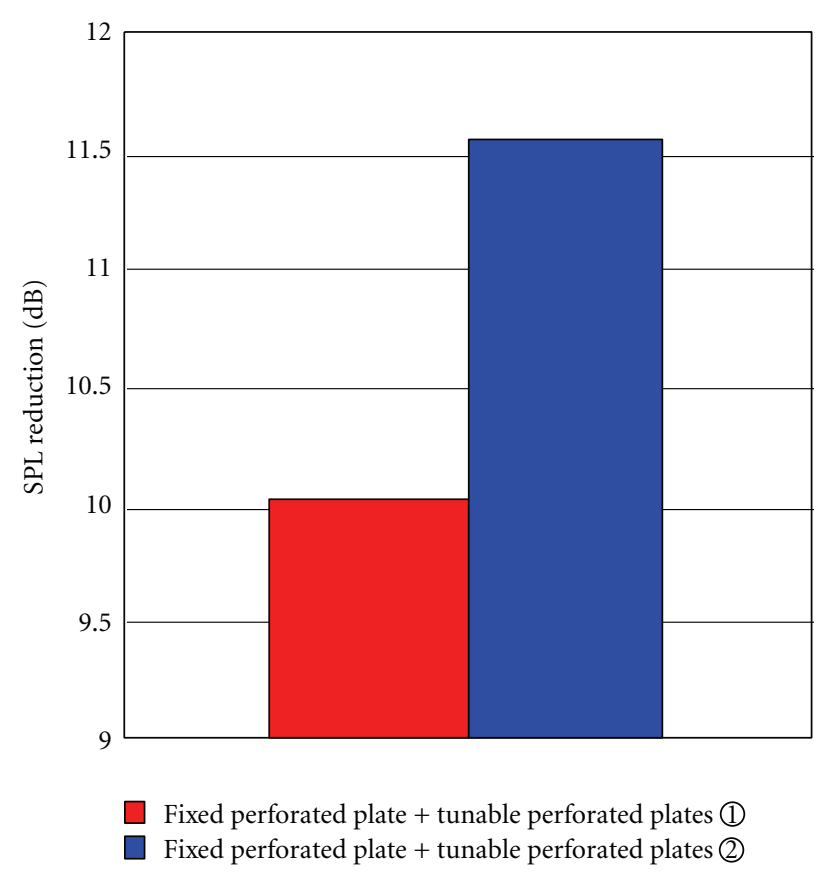

FIGURE 15: Effect of tunable perforated plate hole diameter on overall fan noise reduction by adaptive duct liner II of AAC technology II model. Fan rotational speed $4000 \mathrm{rpm}$; acoustic measuring point 60 deg.; fixed perforated plate hole dia. $=1.0$; pitch $=2.0$; acoustic absorbent material stuck on plate; poal + acousticel.

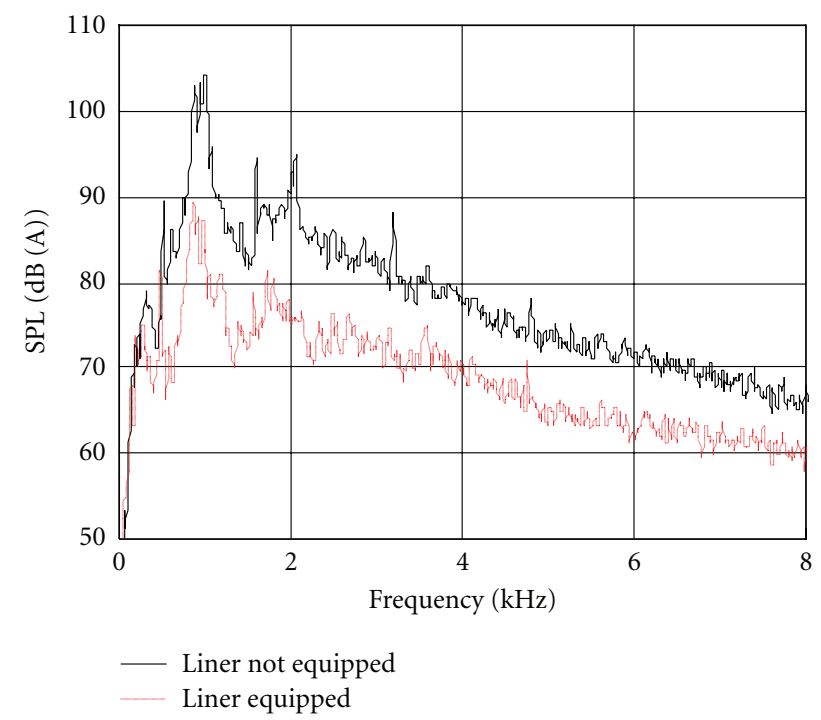

FIGURE 16: Fan noise spectra emitted from duct liner II of AAC technology III model and emitted from hard wall duct. Fan rotational speed $6000 \mathrm{rpm}$; acoustic measuring point $60 \mathrm{deg}$.

creases in the frequency region of $0.3 \sim 0.7 \mathrm{kHz}$ however, in the frequency region of $0.7 \sim 1.2 \mathrm{kHz}$, fan noise absorption decreases. The experimental results describe that the choice of the acoustic absorbent materials is important in determining the absorbed frequency region. 


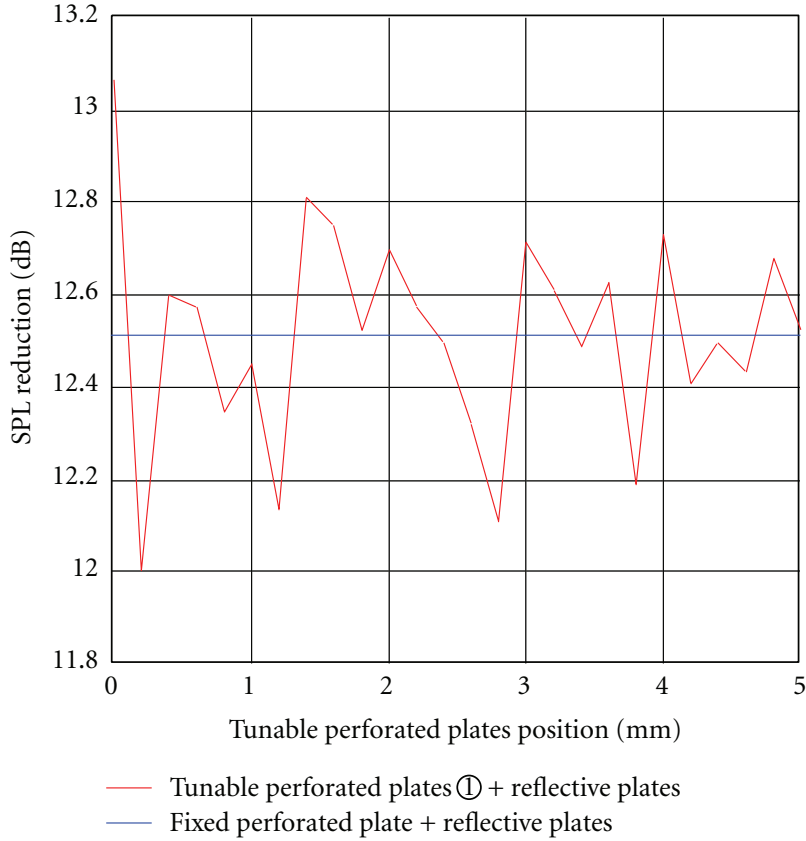

FIGURE 17: Variation of overall fan noise reduction by AAC technology III model with tunable perforated plate position change. Fan rotational speed $4000 \mathrm{rpm}$; acoustic measuring point 45 deg.; mobile reflective plate position fixed at $25 \mathrm{~mm}$; parallel shift.

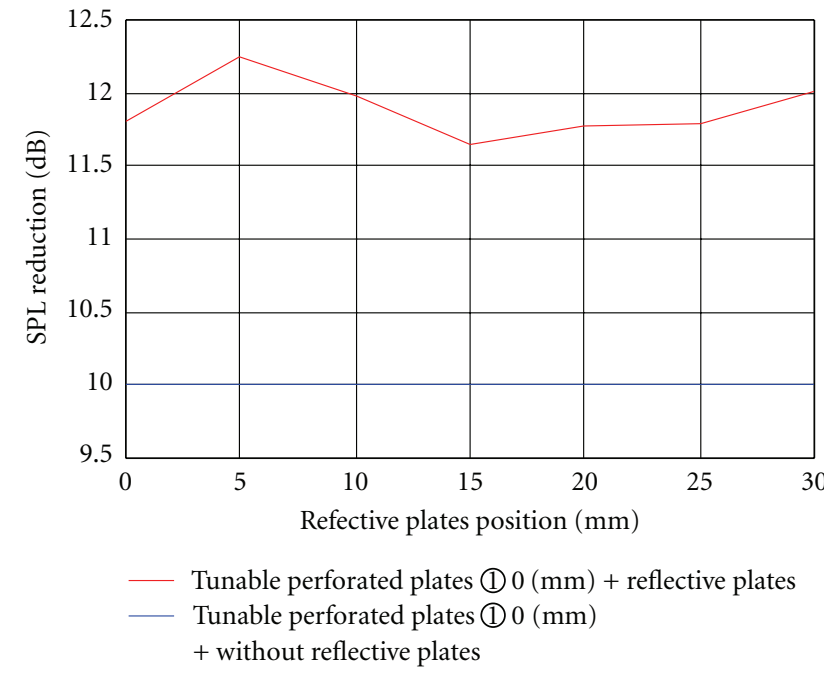

FIGURE 18: Variation of overall fan noise reduction by duct liner II of AAC technology III model.

4.4. Comparison of Absorption Performance of AAC Technology I, II, and III Models. The comparison of the fan noise absorption performance for three-duct liner II of the AAC technology I model, the AAC technology II model, and the AAC technology III model is illustrated in Figure 20, at the two fan rotational speeds of $4000 \mathrm{rpm}$ and $6000 \mathrm{rpm}$. At $4000 \mathrm{rpm}$, the fan noise reduction in the AAC technology I model and in the AAC technology III model is larger than the ones in the AAC technology II model. For the AAC technology I model and the AAC technology III model, the

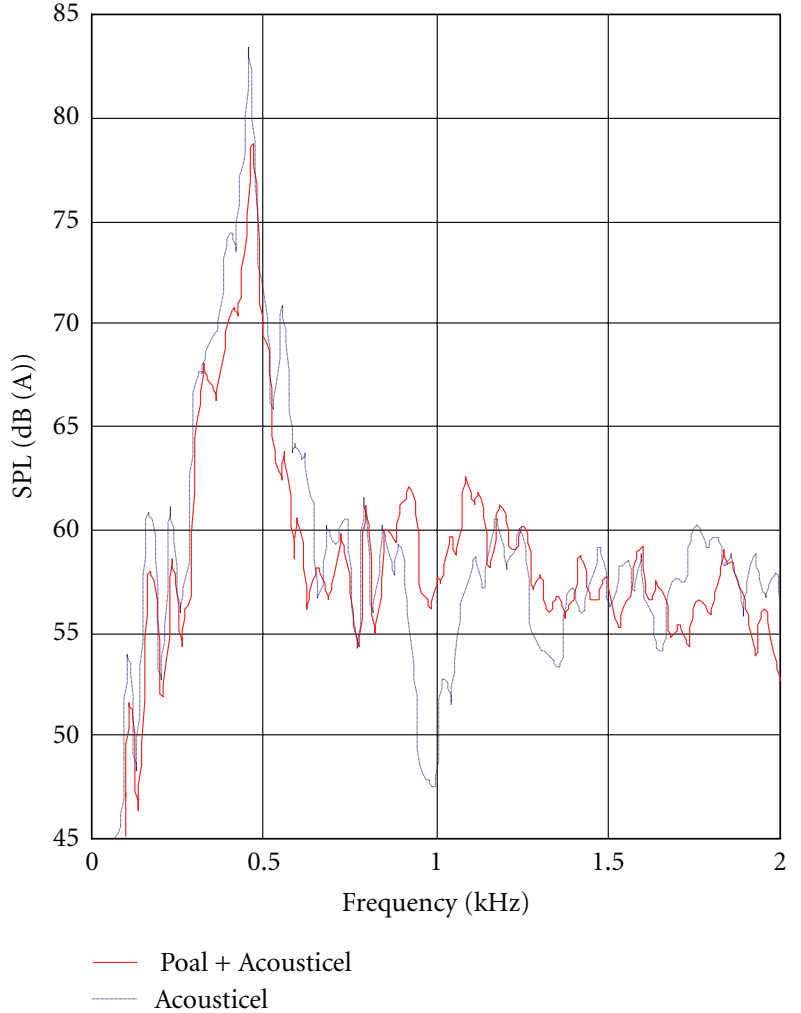

Figure 19: Effect of acoustic absorbent material on fan noise spectra emitted from duct liner II of AAC technology III model. Fan rotational speed $3000 \mathrm{rpm}$; acoustic measuring point $60 \mathrm{deg}$.; with mobile reflective plate; parallel shift; $25 \mathrm{~mm}$ position fixed; without tunable perforated plate.

fan overall SPL noise reduction increases towards $45 \mathrm{deg}$. and the value becomes maximum at $45 \mathrm{deg}$. The large fan Overall SPL noise reduction between $45 \mathrm{deg}$. and $90 \mathrm{deg}$. is $12.0 \sim 13.0 \mathrm{~dB}$ (A). For the AAC technology II model, the same tendency towards polar angular position as the AAC technology I is shown but the reduction value is small to be $10.0 \mathrm{~dB}(\mathrm{~A})$; while, at the fan rotational speed of $6000 \mathrm{rpm}$, the fan noise reduction value of the AAC technology III model is a little larger than the ones of the AAC technology I model and of the AAC technology II model. The tendency of the noise reduction increment towards increasing polar angle position at $6000 \mathrm{rpm}$ is the same as the ones at $4000 \mathrm{rpm}$. In the AAC technology III model, fan noise reduction of $14.8 \mathrm{~dB}(\mathrm{~A})$ is achieved and its value is larger than the ones of the AAC technology I model and of the AAC technology II model. These experimental results made clear that the AAC technology III model and the AAC technology I model are more excellent than the AAC technology II, for fan noise reduction. In the case when the mobile reflective plates and the tunable perforated plates are fixed at the position where the duct liner II can obtain the maximum reduction value, the fan overall SPL noise reduction level was shown to be smaller by $1.0 \sim 2.0 \mathrm{~dB}(\mathrm{~A})$ than in the case when duct liner II is used as the adaptive acoustic impedance control duct liner. However, by fixing the control assembly of both the 


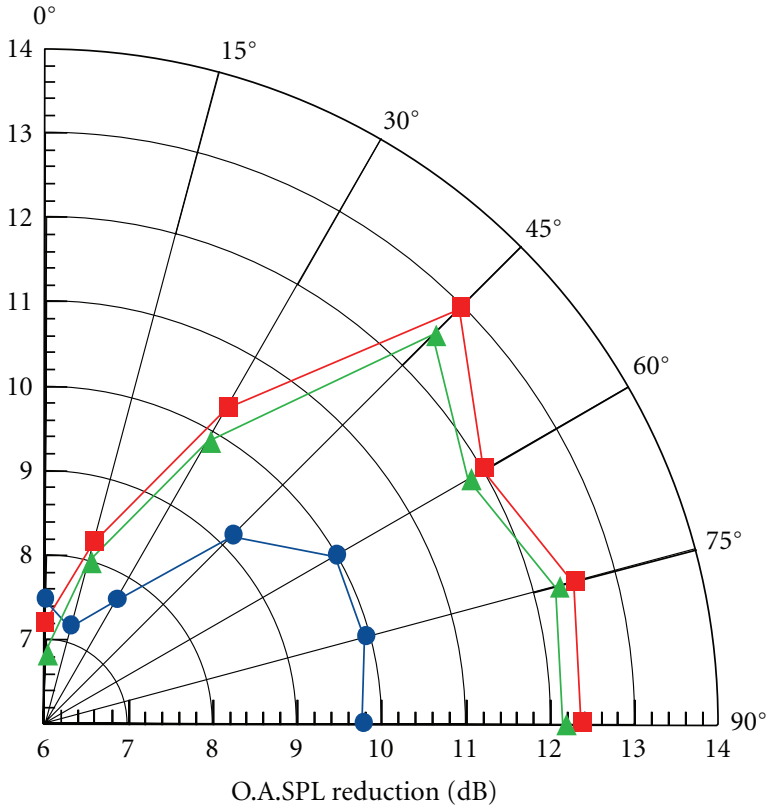

AAC I technology form reflective plate-parallel shift mode $30 \mathrm{~mm}$

- AAC II technology form tunable perforated plates $0 \mathrm{~mm}$

- AAC III technology form reflective plates and tunable perforated plates

(a) Fan rotating speed $4000 \mathrm{rpm}$

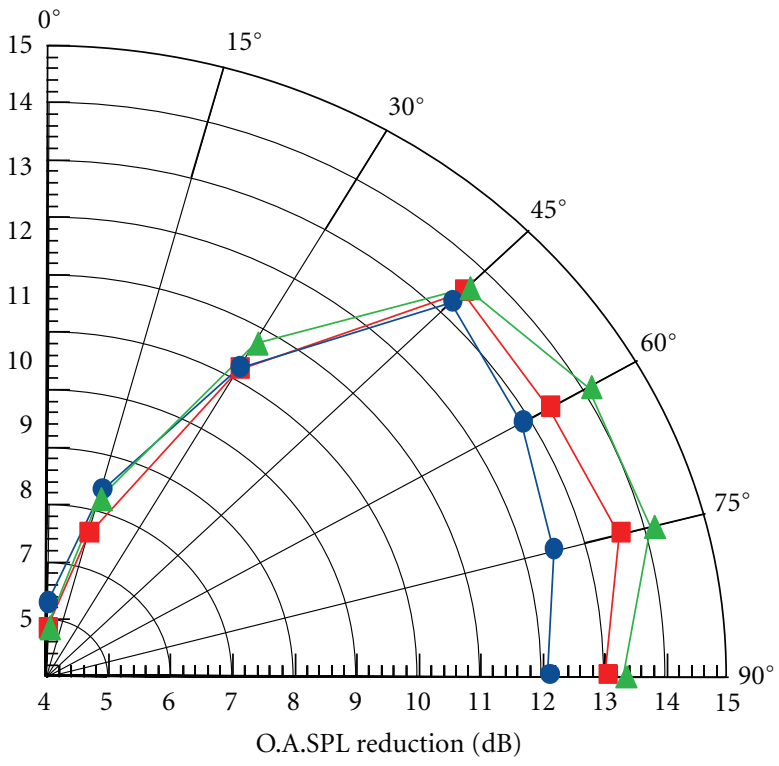

- AAC I technology form reflective plate-parallel shift mode $30 \mathrm{~mm}$

- AAC II technology form tunable perforated plates $0 \mathrm{~mm}$

$\triangle$ AAC III technology form reflective plates and tunable perforated plates

(b) Acoustic absorbent material; poal + acousticel

FIGURE 20: Comparison of overall fan noise reduction by three-duct liner II of AAC technology I model, AAC technology II model and AAC technology III model.

mobile reflective plate and the tunable perforated plate or by removing them from the duct liner, such a lot of merits of the apparatus compactness, of the decrease of the duct liner price, and of the large weight reduction of the duct liners can be obtained.

\section{Conclusion}

For overcoming the stringent aircraft noise regulation and solving the recent aircraft noise issues at night flight, the adaptive acoustic impedance control (AAC) technology I, II, and III models were contrived and developed as the fan noise reduction part of the active engine noise control technology for the current and future aircraft propulsion. Following the development of the AAC Technology I, the AAC technology III was contrived and developed, using both the mobile reflective plate apparatus (AAC technology I model) and the tunable perforated plate apparatus (AAC technology II model) set in the acoustic duct liner and by adaptively adjusting reactance and resistance of the acoustic duct liner impedance. For the actual proof of the AAC technology III performance, the advanced fan noise absorption control duct liner II was made on trial basis with the simple control apparatus and the plain device. The duct liner II was examined for each of the AAC technology I, II, and III models, using the high speed fan test facility.

The test results made clear that the duct liner II is available as the excellent fan noise suppressor for the current and future aircraft engines and can be also applied to wide fields of the turbomachinery noise and the factory noise reduction. It can achieve the fan noise reduction higher than O.A. SPL $10 \mathrm{~dB}$ (A) at the max fan speed $6000 \mathrm{rpm}$, containing the reduction of fundamental BPF tone of $18 \mathrm{~dB}$ and of 2 nd BPF tone of $10 \mathrm{~dB}$ in response to the fan speed change from $3000 \mathrm{rpm}$ to $6000 \mathrm{rpm}$. Also, it was clarified that the tunable perforated plate apparatus (AAC technology II model) is ineffective to the fan noise reduction, in the comparison with the mobile reflective plate apparatus (AAC technology I model).

This paper describes development of the AAC technology I, II, and III and the main results of the actual proof test of the technologies I, II, and III models with the acoustic duct liner II.

Main concluding remarks are as follows.

(1) The AAC technology I, II, and III models are the new adaptive noise absorption control technology which uses the simple apparatus and the plain control device assembly. They are different from 
the recently developed active noise control (ANC) technology which has the complex apparatus and the complicated control device assembly necessary for the acoustic mode detection, the data reduction, and the acoustic cancellation.

(2) The fan noise absorption in the low frequency region from $300 \mathrm{~Hz}$ to $1000 \mathrm{~Hz}$ is largely reinforced by removing the honeycomb panel structure from the duct liner and by enlarging the acoustic resonant chamber and the absorbent chamber in the AAC technology I, II, and III models. In addition, the mobile reflective plate can achieve both the large peak frequency shift and the big peak level increase of the acoustic absorption spectra, in response to fan speed change.

(3) The fan overall SPL noise reduction of $14.8 \mathrm{~dB}$ (A) including the fan 1st BPF tone noise reduction of $18.0 \mathrm{~dB}$ is achieved by the duct liner II of the AAC technology III model. The AAC technology I model can reduce the same fan noise level as the ones obtained by the AAC technology III model. However, the AAC technology II has lower frequency fan noise reduction performance than the AAC technology III model.

(4) In the fan noise reduction, the mobile reflective plate apparatus is more effective and is more responsible for the fan noise spectra change than the tunable perforated plate apparatus. The fan noise reduction of 1.5 to 2.0 times of the ones obtained by the conventionally used acoustic duct liners can be achieved by moving the mobile reflective plates and by controlling it in the AAC technology I and III models.

(5) The duct liner II has the great possibility of the more fan noise reduction by the use of the more efficient acoustic absorbent materials stuck on the acoustic resonant chamber and on the mobile reflective plates. Therefore, the choice of the adaptive acoustic absorbent materials is important for reinforcement of the fan noise reduction performance. Also, it has the great possibility to be easily extended to the selfcontrolled smart acoustic-lined duct using the very simple feedback loop to find the lowest overall sound pressure value of fan noise. The adaptive duct liner II has the great possibilities for overcoming the ICAO Chapter 4 for the fan noises of the supersonic and subsonic aircraft transports.

(6) The acoustic absorption control silencers and the panel liners developed as the application of the experimental results of these AAC technology I, II, and III models can be used for the improvement noise issues in the wide engineering fields of the traffics, the mechanics, the electronics, the architecture, and the civil.

\section{Acknowledgment}

The authors would like to thank many staffs at JAXA, Sugawara N., Takeda K., Takamori S., and students Endo H. and Nishimoto Y. for helpful discussion and assistant on this experiment.

\section{References}

[1] R. H. Thomas, R. A. Burdisso, C. R. Fuller, and W. F. O'Brien, "Preliminary experiments on active control of fan noise from a turbofan engine," AIAA-93-0597, 1993.

[2] T. Ishii, H. Kobayashi, and H. Oinuma, "Modal technique for active control of tones radiated from a ducted fan," Journal of Aircraft, vol. 35, no. 5, pp. 754-760, 1998.

[3] E. Envia, "Fan noise reduction: an overview," International Journal of Aeroacoustics, vol. 1, no. 1, pp. 43-64, 2002.

[4] R. J. Gaeta Jr. and K. K. Ahuja, "A tunable acoustic liner," AIAA-98-2298, 1998.

[5] C. E. Feiler and E. W. Conrad, "Fan noise from turbofan engines," Journal of Aircraft, vol. 13, no. 2, pp. 128-134, 1976.

[6] H. H. Hubbard, Aeroacoustics of Flight Vehicles: Theory and Practice; Volume 1: Noise Source and Volume 2: Noise Control, NASA Reference Publication 1258, 1991.

[7] C. M. Darden, E. D. Olson, and E. W. Shields, "Elements of NASA's high-speed research program," AIAA-93-2942, 1993.

[8] H. Kobayashi, M. Koh, S. Ozaki, M. Yokochi, and T. Sato, "Newly-developed adaptive noise absorption control technology for high speed fan noise reduction," JSME International Journal, Series C, vol. 49, no. 3, pp. 703-712, 2007.

[9] H. Kobayashi, "Actively-controlled sound absorption panel system using mobile reflective plate," patent no. 3554764, May 2004., US-2002-0061110-A1, May 2002.

[10] H. Kobayashi et al., "Research on new technology for activelycontrolled aircraft engine noise reduction," in Asian Joint Conference on Propulsion and Power (AJCPP '05), Kyushu, Japan, January 2005, paper-AJCPP-A2008. 

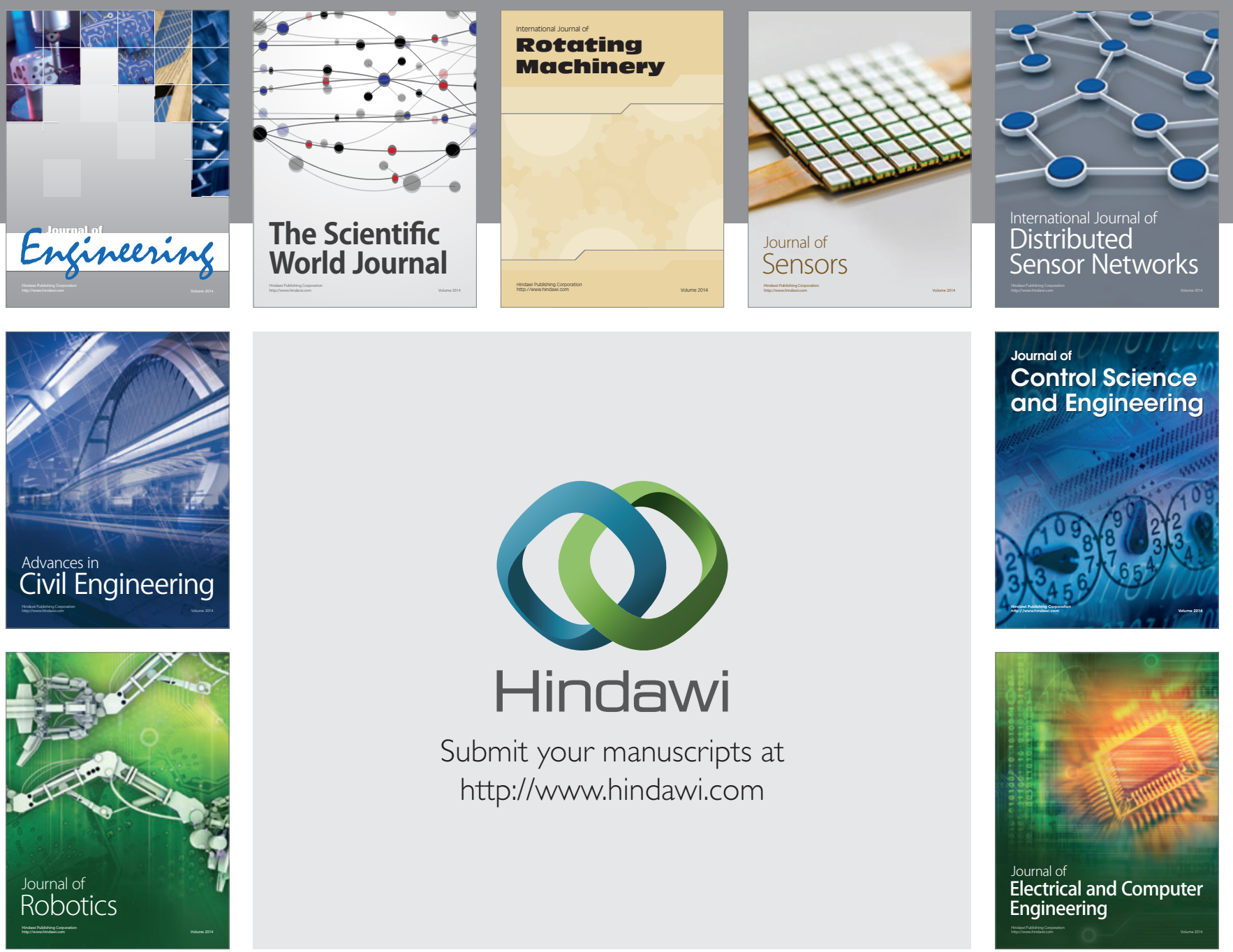

Submit your manuscripts at

http://www.hindawi.com
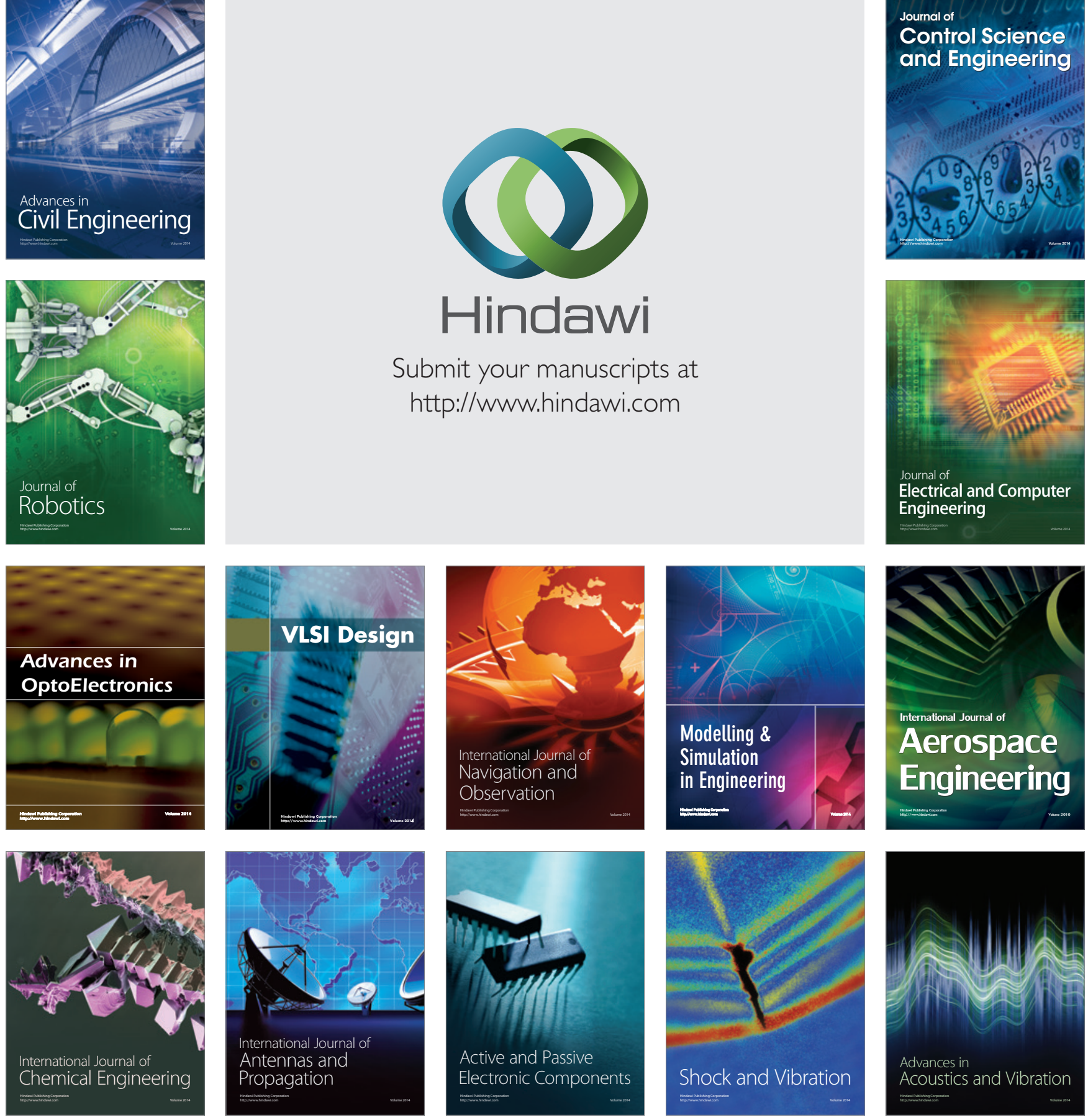